\title{
Thoracic changes and exercise capacity in patients with adolescent idiopathic scoliosis
}

\author{
Alterações torácicas e capacidade de exercício em \\ pacientes com escoliose idiopática do adolescente
}

\author{
Bruna Marques de Almeida Saraiva, Thamiê Cristina Stella, Geferson da Silva Araujo, \\ Evandro Fornias Sperandio, Victor Zuniga Dourado, Milena Carlos Vidotto*
}

\begin{abstract}
Introduction: The spine deformity due to adolescent idiopathic scoliosis (AIS) generates respiratory mechanical limitations that may reduce the physical activity performance. Objective: To evaluate the thoracic deformity, exercise capacity and lung function in AIS patients comparing to healthy adolescentes. Besides investigating associations between thoracic deformity and exercise capacity in AIS patients. Methods: Thirty-two AIS patients and 22 healthy adolescents underwent chest wall evaluation by photogrammetry. We created thoracic markers shaped as angles (A): A3 (xiphoid process and the last false rib on the right and left sides) and A5E (inframamilar / inferior angle of the scapula / left acromion). Individuals were submitted to incremental shuttle walk test (ISWT) and physiological responses were quantified: oxygen consumption $\left(\mathrm{VO}_{2}\right)$, tidal volume (VT), minute ventilation (VE), the rate of gas exchange (R) and the walked distance (ISWD). Pulmonary function test was performed and the forced vital capacity (FVC) and expiratory volume in first second (FEV 1 ) were obtained. Results: Patients with AIS presented FVC $(\mathrm{p}=0.015), \mathrm{FEV}_{1}(\mathrm{p}=0.044), \mathrm{VO}_{2}(\mathrm{p}=0.015), \mathrm{VO}_{2} / \mathrm{kg}(\mathrm{p}=0.008), \mathrm{VT}(\mathrm{p}<0.001), \mathrm{VE}$ $(p=0,010)$ and ISWD significantly reduced compared to healthy adolescents. We found moderate correlations
\end{abstract}

\footnotetext{
BMAS: Doctoral student, e-mail: brunalmeidam@gmail.com

TCS: BS, e-mail: sct.thamie@uol.com.br

GSA: MS, e-mail: gefisio21@yahoo.com.br

EFS: PhD, e-mail: evandrosperandio@yahoo.com

VZD: PhD, e-mail: vzdourado@yahoo.com.br

MCV: PhD, e-mail: milenavidotto@hotmail.com
} 
between the thoracic markers $\mathrm{A} 5 \mathrm{E}$ and $\mathrm{VO}_{2}(\mathrm{r}=-0.480, \mathrm{p}=0.001), \mathrm{A} 3$ and $\mathrm{VE} / \mathrm{VO}_{2}(\mathrm{r}=-0.480 ; \mathrm{p}=0.001)$ and $R(r=-0.480, p=0.001)$ in AIS patients. Conclusion: Patients with AIS presented reduced exercise capacity and reduced pulmonary function. The thoracic deformity is related to worse exercise capacity in individuals with AIS.

Keywords: Scoliosis. Lung Function Test. Photogrammetry. Physical Fitness.

\section{Resumo}

Introdução: A deformidade da coluna vertebral causada pela escoliose idiopática do adolescente (EIA) gera limitações respiratórias que podem reduzir o desempenho da atividade física. Objetivo: Avaliar a deformidade torácica, capacidade de exercício e função pulmonar em pacientes com EIA comparando com adolescentes saudáveis. Além de investigar associações entre a deformidade torácica e capacidade de exercício em pacientes com EIA. Métodos: Trinta e dois pacientes com EIA e 22 adolescentes saudáveis foram submetidos à avaliação da caixa torácica por fotogrametria. Criamos marcadores torácicos em forma de ângulos (A): A3 (processo de xifóide e as últimas costelas falsas bilateral) e A5E (inframamilar/ângulo inferior da escápula/acrômio esquerdo). Os indivíduos foram submetidos ao Incremental Shuttle Walk Test (ISWT) e respostas fisiológicas foram quantificadas: consumo de oxigênio $\left(\mathrm{VO}_{2}\right)$, volume corrente (VT), ventilação minuto (VE), taxa de troca gasosa (R) e a distância percorrida (ISWD). A função pulmonar foi realizada e a capacidade vital forçada (CVF) e o volume expiratório forçado no primeiro segundo (VEF $\left.F_{1}\right)$ foram obtidos. Resultados: Os pacientes com EIA apresentaram CVF ( $p=0,015), V E F_{1}(p=0,044), V O_{2}(p=0,015), V T(p<0,001), V E(p=0,010) e$ ISWD significantemente reduzidos em relação ao controle. Encontramos correlações moderadas entre A5E $e$ $\mathrm{VO}_{2}(r=-0,480, p=0,001), A 3$ e VE $/ \mathrm{VO}_{2}(r=-0,480 ; p=0,001)$ e $R(r=-0,480, p=0,001)$ em pacientes com EIA. Conclusão: Pacientes com EIA apresentaram redução da capacidade de exercício e da função pulmonar e a deformidade torácica está relacionada à pior capacidade de exercício nestes indivíduos.

Palavras-chave: Escoliose. Teste de Função Pulmonar. Fotogrametria. Aptidão Física.

\section{Introduction}

Scoliosis is a three-dimensional deformity of the spine, with lateral curvature and vertebral rotation, which causes thoracic structures asymmetry [1,2]. The idiopathic form constitutes about $90 \%$ of all cases of scoliosis, the most common affects adolescents, which prevails in females with right upper thoracic curvature [3 - 5].

Several factors are related to curve progression, such as sexual and skeletal immaturity and degree of curvature. Due to skeletal maturation, the younger the patient, the greater the chance of progression. Angulation curvatures between $25^{\circ}$ and $40^{\circ}$ have a higher chance of increase as well as those located in the thoracic region [6]. After maturity, curves above $50^{\circ}$ tend to increase on average $1^{\circ}$ per year $[5,7,8]$.

The spinal deformity progresses with the combination of factors such as vertebral rotation, rib deformities, and possible limitations of respiratory muscles, which combined change the chest wall biomecanics. In addition to respiratory impairment, the thoracic deformity may cause limitation to exercise and impact on activities of daily living $[5,9,10]$.

Pulmonary problems are often reported in adolescents with spinal curvature greater than $45^{\circ}$, and patients with moderate curvatures $\left(<45^{\circ}\right)$ may have lung capacity values similar to normal(5). Pulmonary dysfunction is not the only limitation in exercise in patients with scoliosis. The physical deconditioning, the reduction of muscle mass and the compensatory postures adopted are also consequences of the physical activity reduction $[1,11,12]$.

Previous studies on adolescent idiopathic scoliosis (AIS) patients reported spine deformity but did not quantify thoracic deformity. Thoracic alterations can be measured using computerized photographic, non-invasive, easy to apply methods with reliable reproducibility [13].

The digital photogrammetry allows subtle changes registration and interrelationship between parts of the human body difficult to be measured differently. This method allows us to evaluate 
changes in body segments using angular and linear measurements [14]. Among the programs available for postural analysis by photogrammetry, one option is the Postural Assessment Software (PAS) $[13,15]$.

Considering that changes in scoliosis cause thoracic deformities, changes in the respiratory system, decreased exercise capacity and due to the lack of studies that objectively quantify the changes in the chest wall, this study has become necessary. The aim of this study was to evaluate the thoracic deformity, exercise capacity and lung function in AIS patients compared to healthy subjects. In addition to evaluating the associations between chest and spine alterations with exercise capacity.

\section{Methods}

The cross-sectional study, approved by the Research Ethics Committee of the Federal University of São Paulo (No. 1,349,351), was carried out for six months. After signing the informed consent, 54 subjects were divided into two groups: a control group consisting of healthy adolescents and a scoliosis group of patients diagnosed with adolescent idiopathic scoliosis (AIS).

We included individuals of both genders between the ages of 11 and 18. We excluded those with a previous or current history of heart, lung or neuromuscular diseases; the physically active [16] and those who could not carry out the proposed evaluations. Also, we excluded from the control group adolescents who presented important postural alterations detected in a previous postural evaluation.

The participants were submitted to anamnesis and physical examination composed by weight, height and body mass index (BMI), using a digital scale and stadiometer.

Pulmonary evaluation was performed by spirometry using a portable spirometer (Spiropalm; Cosmed, Pavona di Albano, Italy) following the recommendations of the Brazilian Society of Pulmonology and Tisiology [17]. The forced vital capacity (FVC), the forced expiratory volume in the first second $\left(\mathrm{FEV}_{1}\right)$ and the $\mathrm{FEV}_{1} / \mathrm{FVC}$ ratio in absolute values and percentage of predicted values for the Brazilian population were analyzed [18].

To evaluate the thoracic deformity, the photogrammetry method was used by the Postural
Assessment Software (PAS), following the guideline of the developers. The anatomical points were marked on the skin with the fixation of a $25 \mathrm{~mm}$ in diameter half-sphere of Styrofoam balls using double-sided adhesive tape (Figure 1).

The photos were always analyzed by the same evaluator with experience in the photogrammetry method. Thoracic markers were created in the form of angles (A) and distances (D). All markers were created by our team except the angle A1 [13]. The A4 marker was measured from the deepest point of the waist and its upper and lower edges (Figures 1 and 2).

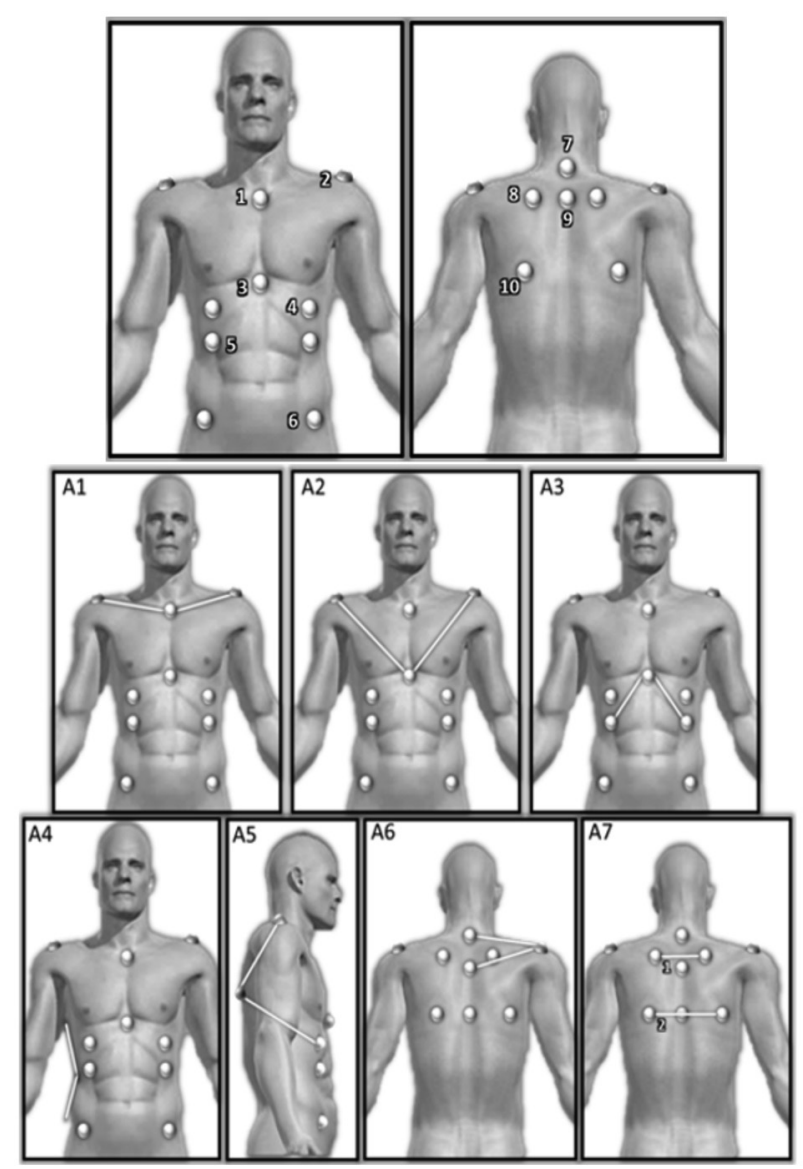

Figure 1 - 1. Manubrium of sternum; 2. Acromion of the scapula; 3. Xiphoid process of sternum; 4. Inframammary region (half the distance between nipple and last false rib); 5 .Last false rib (intersection of nipple line with last false rib); 6.Antero-superior iliac spine (ASIS); 7. C7 spiny process; 8 . Upper angle of the scapula; 9.T3 thymus process; 10. Lower angle of scapula. Al. Right (R) acromion/manubrium/left (L) acromion; A2. R acromion/xiphoid process/L acromion; A3. R Last false rib /xiphoid process/L last false rib; A4. Side deviation of the trunk; A5. Acromion/lower angle of scapula /inframammary; A6. C7/ acromion/T3; A7. Intersection of segments 1 and 2. 


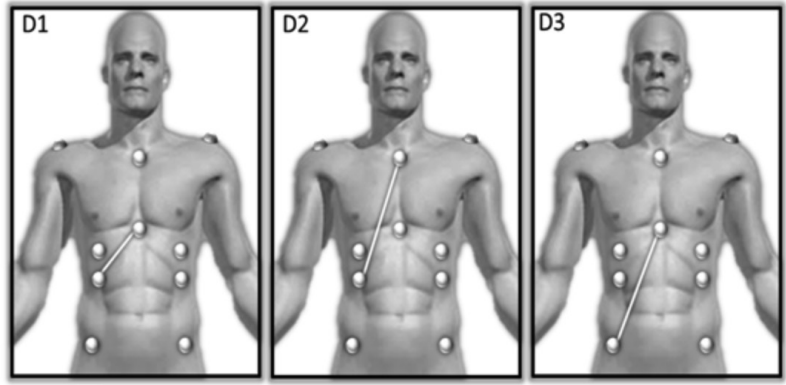

Figure 2 - D1. Xiphoid process/last false rib; D2. Manubrion/ last false rib; D3. Xiphoid process/Antero-superior iliac spine.

To assess exercise capacity, participants underwent two Incremental Shuttle Walk Test (ISWT) [19] with at least a 30 minutes interval between them. Before and after the test were measured: heart rate, blood pressure, dyspnea and fatigue of the lower limbs using the Modified Borg Scale. The criteria for interrupting the test were the presence of chest pain, dyspnea and / or intolerable muscle fatigue, syncope, paleness, cold sweating, among other symptoms suggestive of low cardiac output. The walked distances during the ISWT were expressed in absolute values.

In addition to the above mentioned interruption criteria, the test was interrupted when the subject could not reach the cone at a pre-determined time by the sound signals. However, when the patient reached the cone before the time limit, it was advised to remain in the cone until the next signal sounds.

During the second ISWT, a metabolic system (K4 Cosmed Metabolic Analyzer) was used in which a face mask with minimum dead space $(50 \mathrm{ml})$ was attached to the subject. A pneumotachograph read the expiratory flow and samples of expired gas collected during the test were analyzed.

The following physiological variables were obtained from the data collected during the tests: oxygen consumption $\left(\mathrm{VO}_{2}\right)$, carbon dioxide production $\left(\mathrm{VCO}_{2}\right)$, gas exchange ratio $(\mathrm{R})$, pulmonary ventilation (VE). Then the ventilatory equivalents for oxygen $\left(\mathrm{VE} / \mathrm{VO}_{2}\right)$ and for carbon dioxide (VE $/ \mathrm{CO}_{2}$ ) and oxygen pulse $\left(\mathrm{PuO}_{2}\right)$ were calculated.

The values of $\mathrm{VO}_{2}, \mathrm{VCO}_{2}$ and $\mathrm{VE}$ were considered to be the highest value achieved during the exercise or in the early recovery phase (the first 30 seconds after the end of the test). The $\mathrm{R}$ value considered was the highest value reached at the end of the effort and / or simultaneously with $\mathrm{VO}_{2}$ at the peak of the exercise. The values of $\mathrm{VE} / \mathrm{VO}_{2}$ and $\mathrm{VE} / \mathrm{CO}_{2}$ were considered to be those corresponding to the maximum VE. Other data obtained by the equipment were heart rate (HR) and respiratory rate (RR).

Data were assessed descriptively and calculated mean and standard deviation or median (interquartile range) depending on the distribution of variables. Normality was investigated by the KolmogorovSmirnov test. To compare the means or medians of the variables between the patients with AIS and the control group, the unpaired t test or Mann-Whitney test, respectively, were used. Correlations between the studied variables were evaluated by the Pearson or Spearman correlation coefficients according to the distribution of the variables. The probability of alpha error was set at $5 \%$ for all analyzes.

\section{Results}

The sample consisted of 54 participants, among them 32 adolescents with AIS, 21 in conservative treatment and 11 in the preoperative phase. In the AIS group, $28(87.5 \%)$ were girls with a mean age of 14 years \pm 2; height $1.59 \mathrm{~m} \pm 0.10 ; 47 \mathrm{~kg} \pm 10$, body mass index (BMI) $18.5 \pm 2.6$ and main Cobb angle $40 \pm 16.9$. And the control group consisted of 22 healthy adolescents, with $16(72.7 \%)$ girls, with a mean age of 14 years \pm 2 ; height $1.58 \mathrm{~m} \pm 0.10 ; 49 \mathrm{~kg} \pm 10$ and BMI $19.3 \pm 2.5$. No statistical difference was identified between the groups in the comparison of the described variables.

There was no difference between groups regarding the thoracic markers. Patients with AIS had reduced FVC and $\mathrm{FEV}_{1}$ when compared to control, as well as reduced exercise capacity demonstrated by the reduction of $\mathrm{VO}_{2} / \mathrm{kg}, \mathrm{VCO}_{2}, \mathrm{VE} / \mathrm{VO}_{2}, \mathrm{R}, \mathrm{VT}$ and walking distance variables (Table 1).

Table 1 - Comparison of pulmonary function and variables obtained during IST

\begin{tabular}{lccc}
\hline \multicolumn{1}{c}{ Variables } & AIS & Control & p \\
\hline \multicolumn{2}{l}{ Pulmonary function } & & \\
FVC, L & $2.77 \pm 0.71$ & $3.33 \pm 0.75$ & $0.015^{*}$ \\
FVC predict, \% & $90.10 \pm 15.05$ & $98.30 \pm 15.02$ & 0.062 \\
FEV $_{1}, \mathrm{~L}$ & $2.43 \pm 0.69$ & $2.84 \pm 0.72$ & $0.044^{*}$ \\
FEV $_{1}$ predict, $\%$ & $86.26 \pm 15.44$ & $94.25 \pm 14.43$ & 0.066 \\
FEV $_{1} /$ FVC & $0.87 \pm 0.07$ & $0.85 \pm 0.08$ & 0.517 \\
Metabolics & 1257 & & \\
VO $_{2}, \mathrm{ml} / \mathrm{min}$ & $(936.5-1362.2)$ & $(1197.7-1696.5)$ & $0,015^{*}$ \\
\hline
\end{tabular}

(To be continued) 
(Conclusion)

Table $\mathbf{1}$ - Comparison of pulmonary function and variables obtained during IST

\begin{tabular}{|c|c|c|c|}
\hline Variables & AIS & Control & $\mathrm{p}$ \\
\hline $\mathrm{VO}_{2}, \mathrm{ml} / \mathrm{Kg} / \mathrm{min}$ & $25 \pm 5$ & $29 \pm 5$ & $0.008^{\star}$ \\
\hline $\mathrm{VCO}_{2}, \mathrm{ml} / \mathrm{min}$ & $1307 \pm 505$ & $1644 \pm 525$ & $0.023^{\star}$ \\
\hline $\mathrm{R}, \mathrm{ml} / \mathrm{min} / \mathrm{ml} / \mathrm{min}$ & $1.13 \pm 0.12$ & $1.22 \pm 0.17$ & $0.043^{\star}$ \\
\hline \multicolumn{4}{|l|}{ Ventilatory } \\
\hline VT, L & $1.0 \pm 0.3$ & $1.2 \pm 0.3$ & $0.015^{\star}$ \\
\hline $\mathrm{VE}, \mathrm{L} / \mathrm{min}$ & $41.8(30.6-49.4)$ & $52.9(41.0-62.2)$ & $0.010^{\star}$ \\
\hline $\mathrm{VE} / \mathrm{NO}_{2}$ & $38 \pm 4$ & $42 \pm 7$ & $0.055^{\star}$ \\
\hline $\mathrm{VE} / \mathrm{VCO}_{2}$ & $37.8(35.6-41.9)$ & $39.1(37.3-42.9)$ & 0.350 \\
\hline \multicolumn{4}{|l|}{ Cardiovascular } \\
\hline $\begin{array}{l}\mathrm{PuO}_{2}, \mathrm{ml} / \mathrm{min} / \\
\mathrm{bpm}\end{array}$ & 7.1(6.1-9.0) & $8.2(7.1$ - 10.5) & 0.107 \\
\hline \multicolumn{4}{|l|}{ Walked distance } \\
\hline ISWD1, m & $480 \pm 90$ & $590 \pm 133$ & $0.002^{\star}$ \\
\hline ISWD2, m & $496 \pm 106$ & $632 \pm 121$ & $<0.001^{*}$ \\
\hline
\end{tabular}

Correlations were observed between thoracic markers and metabolic variables in patients with AIS, as shown in Figure 3. The association between the main Cobb angle with $\mathrm{VCO}_{2}(\mathrm{r}=-0.49, \mathrm{p}=0, \mathrm{R}=-0.48, \mathrm{p}=0.03)$, VT $(r=-0.51, p=0.02)$, ISWD $(r=-0.51, p=0.02)$ and HR at the end of the test $(r=-0.62, \mathrm{p}<0.01)$.

Moderate correlations were observed between right A4 thoracic markers (A4R) and FVC ( $\mathrm{r}=-0.43$, $\mathrm{p}=0.02)$ and $\mathrm{FEV}_{1}(\mathrm{r}=-0.49, \mathrm{p}=0.01)$, and between the angle A7 and FVC predicted ( $r=0.046, p=0.03)$.

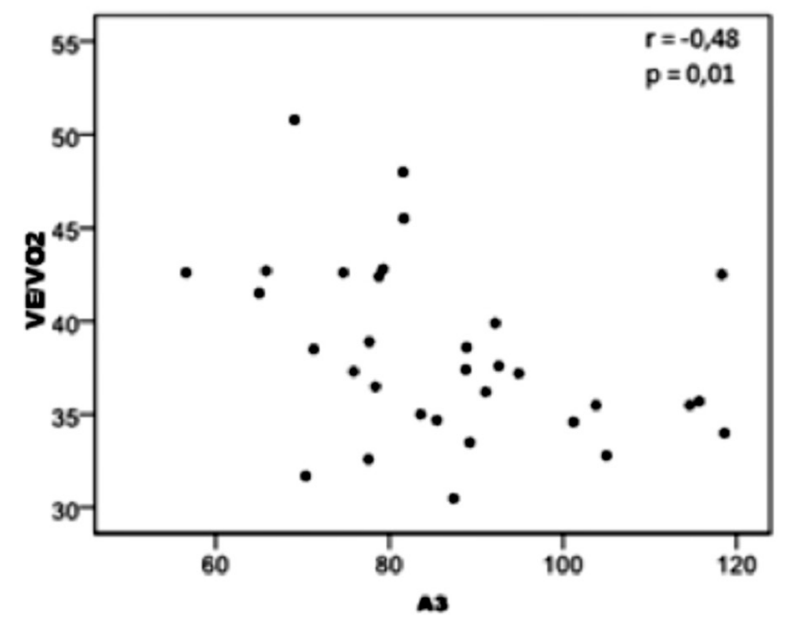

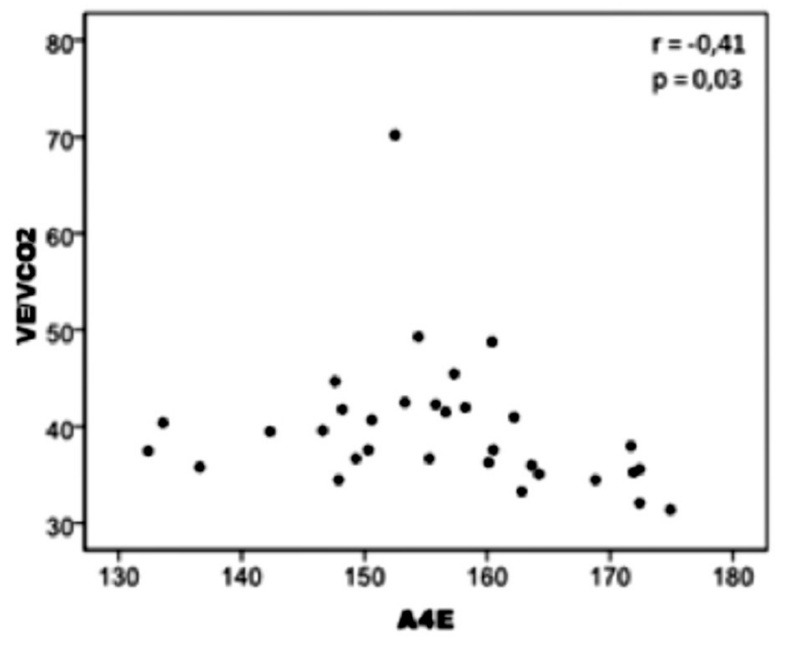
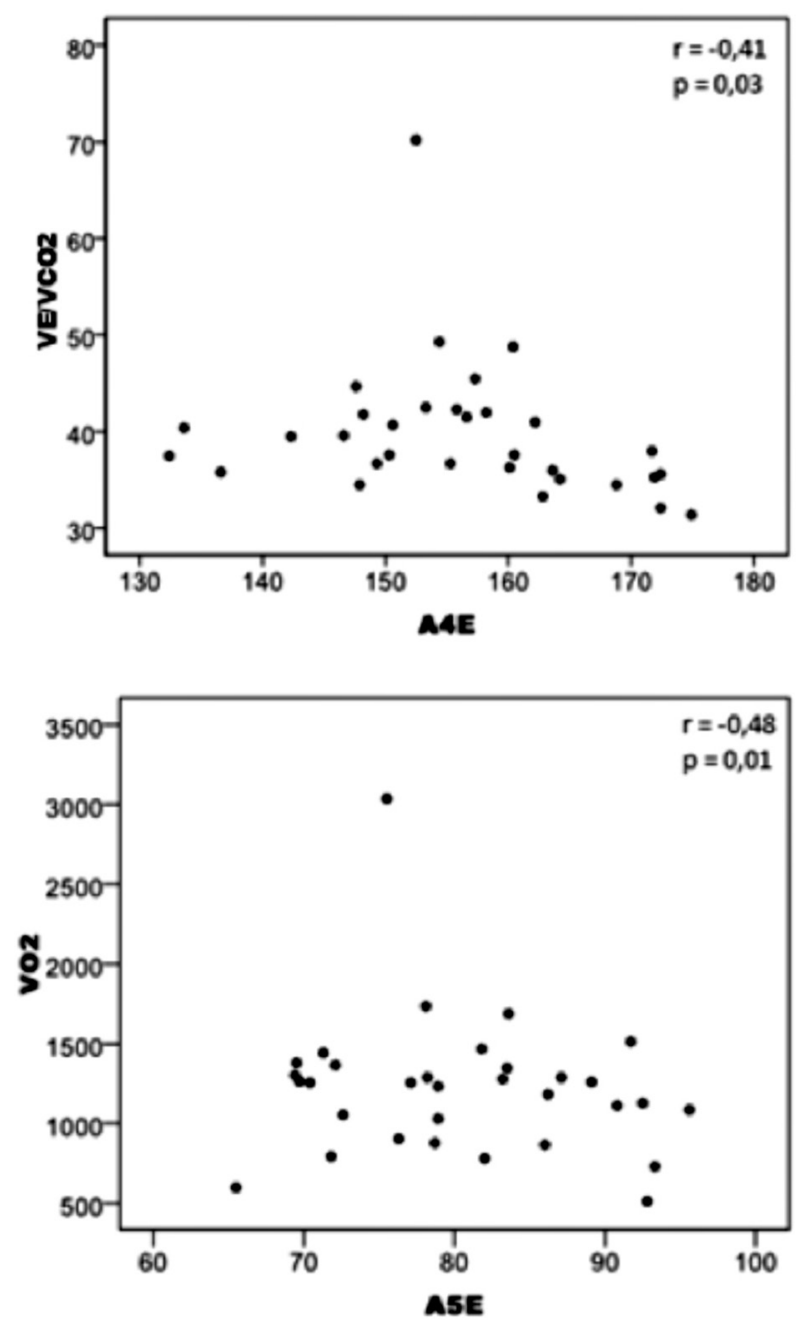

Figure $\mathbf{3}$ - Correlation between te angles obtainded by photogrammetry and metabolic and ventilatory variables 


\section{Discussion}

It was observed that AIS negatively influences exercise capacity and lung function. As well, changes in the chest wall and spine are related to poorer performance during exercise. Other studies have compared the exercise capacity of AIS patients and non-affected individuals, however, they used the six-minute walk test [5] or cycle ergometer test $[11,12,20]$. Few studies used the ISWT to assess aerobic capacity in this population [21], but they did not assess the influence of the thoracic deformity on exercise variables.

In our study, we observed that AIS patients had a decrease in $\mathrm{VO}_{2}, \mathrm{VO}_{2} \mathrm{~kg}$, VE and VT when compared to the control group, as observed in previous studies that also used an incremental exercise protocol $[11,12,20,22]$. The peak of oxygen consumption is an important indicator of an individual's exercise capacity [23]. Therefore, the lower values of $\mathrm{VO}_{2}$ and $\mathrm{VO}_{2} \mathrm{~kg}$ obtained indicate worse exercise capacity in AIS patients when compared to a control group.

Higher values of VE are related to better physical fitness, since endurance athletes have a higher VE in comparison with healthy untrained individuals [23]. Thus, the values found in our study corroborate the hypothesis of worse exercise capacity in individuals with AIS.

We observed reduced $\mathrm{VCO}_{2}$ values in the AIS group, which indicates poor ventilation and $\mathrm{CO}_{2}$ retention. The minute ventilation depends on the tidal volume and the respiratory rate of the individual and has a close relationship with the $\mathrm{VCO}_{2}$ value, but the $\mathrm{VE} / \mathrm{VCO}_{2}$ did not present a statistically significant difference in our study.

The respiratory oxygen balance $\left(\mathrm{VE} / \mathrm{VO}_{2}\right)$ presented a reduction in the AIS group compared to the control, which contradicts an earlier study that observed higher values of this variable at the end of the exercise in AIS patients with curvatures lower than $45^{\circ}$, which indicates ventilatory inefficiency [20]. Such disagreement between studies may have occurred because the scoliosis group analyzed in the current study included patients with milder curvatures under non-surgical treatment.

The value of $\mathrm{R}$ refers to the relationship between $\mathrm{CO}_{2}$ production and $\mathrm{O}_{2}$ consumption, and usually presents values above one during intense exercise [23]. In our study, both the control group and the AIS group presented $\mathrm{R}$ values greater than one, indicating that the test was adequate to evaluate exercise capacity. However, in comparison with healthy individuals, AIS patients had a lower $\mathrm{R}$ value, which was similar to that observed in a previous study [22].

The lower value of $\mathrm{R}$ in the AIS group is related to the reduced values of $\mathrm{VO}_{2}$ and $\mathrm{VCO}_{2}$, which indicates a relation with the worst aerobic capacity. In a previous study that performed a physical training protocol, an increase in $\mathrm{R}$ was observed in the scoliosis group after training [22]. This shows that in this population a lower value of $R$ is also associated with physical deconditioning.

Patients with scoliosis walked shorter distances than the control group in both ISWT. This suggests worse performance during exercise and agrees with the metabolic variables that presented reduced values in the AIS group, which was similar in a study using the 6MWT in subjects with mild and moderate curvatures [5].

As for pulmonary function, only the absolute values of FVC and $\mathrm{FEV}_{1}$ were slightly decreased in the AIS group. The fact that there is no significant change in predicted values pulmonar function is not uncommon, since ventilatory disorders appear not to be associated with mild and moderate curvatures [24].

However, although the pulmonary alterations evaluated at rest do not limit daily life activities, they may worsen during high intensity exercise due to increased ventilatory demand [20]. Thus, although there are no significant changes in spirometry, we can infer that changes in pulmonary volumes and capacities may contribute to worse performance during high intensity physical activity.

Regarding the postural analysis and functional capacity in the AIS group, we observed the correlation between some thoracic markers with the physiological variables obtained during the second ISWT, indicating that thoracic deformity may reflect on the exercise capacity of these individuals.

The thoracic marker $\mathrm{A} 3$ was related to worsening of the gas exchange rate and $\mathrm{VE} / \mathrm{VO}_{2}$ values. The left $\mathrm{A} 5$ angle correlated with the decrease in $\mathrm{VO}_{2}$. The value of $\mathrm{A} 4 \mathrm{~L}$, which indicates the lateral deviation of the trunk, correlated with the worsening of the $\mathrm{VE} / \mathrm{VCO}_{2}$ value.

As the thoracic spine connects to the ribs by costovertebral joints, and the interaction between these components is modified in cases of deformity [25]. In AIS patients is observed that the 
ipsilateral ribs to the concavity are horizontal, while on the convex side they rise [26]. AIS patients present alterations in the costovertebral angle, even in moderate curvatures, which shows that the thoracic deformity does not occur only in severe cases. In this sense, alterations in the orientation of the ribs cause direct modifications in the thoracic markers mentioned above, and are associated with the worsening of exercise capacity in these individuals.

In agreement with this hypothesis, it was observed that the main thoracic Cobb angle also correlated with the distance walked in both ISWT, $\mathrm{CO}_{2}$ production and tidal volume, which means that as the spine deformity progresses, such variables decrease, indicating worse performance and worsening of ventilation during exercise, respectively. Other studies have already analyzed the relationship of the scoliotic curvature increase with worsening in aerobic capacity and obtained similar results $[11,20]$.

The Cobb angle also correlated inversely with respiratory rate, which differs from previous studies [1, 5, 12, 20, 22]. In general, a higher value of RR in AIS individuals during intense exercise denotes an attempt to increase VE after failure to increase VT due to the physical and pulmonary limitations caused by the deformity [24]. This result may have occurred due to the fact that most of the patients with EIA assessed in our study had mild and moderate curvatures. Patients in our study were probably limited to exercise, mainly due to physical deconditioning and muscle weakness and not to ventilatory changes [5].

The thoracic Cobb angle also showed an inverse correlation with the heart rate obtained during the ISWT and the walked distance. This allows us to conclude that the modification in the chest wall structure leads to exercise capacity limitations, but not related to cardiovascular alterations.

A lower HR at the peak of exercise in AIS patients compared to healthy subjects was observed in studies that analyzed responses to an incremental test $[12,22]$. This occurs because in AIS patients the interruption of exercise occurs before the maximum HR is reached, so the exercise limitation occurs due to other reasons and not for cardiovascular impairment. A previous study observed that the maximum HR and the anaerobic threshold were lower in the scoliosis group than in the control group [22].

The studies have correlated the variables of cardiorespiratory fitness only with the spine curvature. To our knowledge, no study correlated thoracic deformity with the metabolic, ventilatory, and cardiovascular variables obtained in a walking test.

In our study, no significant correlation was observed between pulmonary function and the Cobb angles, but the FVC (absolute and predicted) and FEV1 presented a correlation with two thoracic markers. The thoracic marker A4R correlated with the absolute values of lung function, as this angle increases, the individual's lung capacity worsens. The thoracic marker A7 presented a direct correlation with the predicted value of FVC.

Assuming that the most common AIS curvature is the thoracic convexity on the right [3], which generates rotation and elevation of the ribs ispsilaterally [26], we can suggest that the increase of $A 4 R$ is directly related to the spine deformity, therefore, the worsening of the function pulmonary. The thoracic marker A7 may be altered when misalignment occurs between the shoulder blades, which depends directly on the alignment of the spine and chest wall. In this sense, we can assume that thoracic deformity in AIS individuals are related to worsening pulmonary function.

Rotation of the vertebrae laterally displaces the ribs and sternum, causing deformation and flattening of the lungs, which contributes to the restrictive pattern in the lung function of individuals with scoliosis [24, 27]. The alteration in the sagittal diameter of the rib cage, the rotation of the T8 and T9 vertebrae and the consequent reduction of the lung area led to a lower vital capacity [28, 29].

Although we have found evidence that worsening curvature and concomitante thoracic deformity have an effect on functional exercise capacity in the AIS group, other findings demonstrate that exercise limitation is not directly related to ventilatory impairment.

The reasons for the worst performance in physical activity in AIS patients with mild and moderate curvatures are widely discussed in the literature. One study observed that individuals with scoliosis have weakness in the peripheral musculature [12]. It is believed that the muscular dysfunction observed in these patients may be related to genetic causes and thus be a contributing factor for the spine deformation, and not a consequence [30]. Considering this relationship between respiratory and peripheral muscular dysfunction with scoliosis, it is natural to conclude that the worst functional capacity of exercise is related not only to ventilatory factors. 
The thoracic deformity changes the diaphragm efficiency, since the twist hemicúpula leads to change of its radius and thus reduce its power generation, which associated with weakness of respiratory muscles by abnormal configuration of the ribs leads to an increase in respiratory work and consequent fatigue [24].

In this sense, this work was important because it was possible to demonstrate the presence of correlation between the changes of chest wall with physical fitness and lung function in patients with AIS, indicating that the thoracic deformity due to AIS, is a factor important to be evaluated and considered. In addition to highlighting the possibility of using the Incremental Shuttle Wakl Test (ISWT) as a field test to evaluate exercise capacity in patients with AIS, since there is scarce literature in this population.

Among the limitations of the study, a separate evaluation was not made between individuals with lumbar and thoracic principal curvature or between right and left bends, which could alter the evaluation findings of thoracic markers and their correlation with variables of exercise capacity and pulmonary function. Another limiting factor of the study was the non-inclusion of respiratory muscle strength assessment, which could present important data for the interpretation of exercise limiting factors in this population.

\section{Conclusion}

We can conclude that AIS patients have reduced exercise capacity and reduced pulmonary function. In addition, the thoracic and spine deformity may justify its worse physical performance. This finding demonstrates the importance of both conservative and surgical treatment that seeks to reduce the deformity generated by idiopathic adolescent scoliosis.

\section{References}

1. Alves VLS, Avanzi O. Objective assessment of the cardiorespiratory function of adolescents with idiopathic scoliosis through the six-minute walk test. Spine (Phila Pa 1976). 2009;34(25):E926-E9.

2. Grivas TB, Vasiliadis ES, Mihas C, Savvidou O. The effect of growth on the correlation between the spinal and rib cage deformity: implications on idiopathic scoliosis pathogenesis. Scoliosis. 2007;2:11.
3. Konieczny MR, Senyurt H, Krauspe R. Epidemiology of adolescent idiopathic scoliosis. J Child Orthop. 2013;7(1):3-9.

4. Huynh AM, Aubin CE, Rajwani T, Bagnall KM, Villemure I. Pedicle growth asymmetry as a cause of adolescent idiopathic scoliosis: a biomechanical study. Eur Spine J. 2007;16(4):523-9.

5. Alves VLS, Stirbulov R, Avanzi O. Impact of a physical rehabilitation program on the respiratory function of adolescents with idiopathic scoliosis. Chest. 2006;130(2):500-5.

6. Weinstein SL, Dolan LA, Cheng JCY, Danielsson A, Morcuende JA. Adolescent idiopathic scoliosis. Lancet. 2008;371(9623):1527-37.

7. Arlet V, Reddi V. Adolescent Idiopathic Scoliosis. Neurosurg Clin N Am. 2007;18(2):255-9.

8. Martelli RC, Traebert J. Estudo descritivo das alterações posturais de coluna vertebral em escolares de 10 a 16 anos de idade: Tangará-SC, 2004. Rev Bras Epidemiol. 2006;9(1):87-93.

9. Johnston CE, Richards BS, Sucato DJ, Bridwell KH, Lenke LG, Erickson M. Correlation of preoperative deformity magnitude and pulmonary function tests in adolescent idiopathic scoliosis. Spine (Phila Pa 1976). 2011;36(14):1096-102.

10. Cabral LTB, Valesin Filho ES, Ueno FH, Yonezaki AM, Rodrigues LMR. Avaliação da qualidade de vida em pacientes com escoliose idiopática do adolescente após tratamento cirúrgico pelo questionário SF-36. Coluna/Columna. 2009;8(3):315-22.

11. Czaprowski D, Kotwicki T, Biernat R, Urniaz J, Ronikier A. Physical capacity of girls with mild and moderate idiopathic scoliosis: Influence of the size, length and number of curvatures. Eur Spine J. 2012;21(6):1099-105.

12. Martínez-Llorens J, Ramírez M, Colomina MJ, Bagó J, Molina A, Cáceres E, et al. Muscle dysfunction and exercise limitation in adolescent idiopathic scoliosis. Eur Respir J. 2010;36(2):393-400.

13. Davidson J, Santos AMN, Garcia KMB, Yi LC, João PC, Miyoshi MH, et al. Photogrammetry: An accurate and reliable tool to detect thoracic musculoskeletal abnormalities in preterm infants. Physiotherapy. 2012;98(3):243-9. 
14. Watson AW, Mac Donncha C. A reliable technique for the assessment of posture: Assessment criiteria for aspects of posture. J Sports Med Phys Fitness. 2000;40(3):260-70.

15. Souza JA, Pasinato F, Basso D, Corrêa ECR, Silva AMT. Biofotogrametria confiabilidade das medidas do protocolo do software para avaliação postural (SAPO). Rev Bras Cineantropom Desempenho Hum. 2011;13(4):299-305.

16. Garber CE, Blissmer B, Deschenes MR, Franklin BA, Lamonte MJ, Lee IM, et al. Quantity and quality of exercise for developing and maintaining cardiorespiratory, musculoskeletal, and neuromotor fitness in apparently healthy adults: Guidance for prescribing exercise. Med Sci Sports Exerc. 2011;43(7):1334-59.

17. Pereira CAC. Espirometria. J Pneumol. 2002;28(Suppl 3):S1-S82.

18. Pereira CAC, Sato T, Rodrigues SC. Novos valores de referência para espirometria forçada em brasileiros adultos de raça branca. J Bras Pneumol. 2007;33(4):397-406.

19. Singh SJ, Morgan MD, Scott S, Walters D, Hardman AE. Development of a shuttle walking test of disability in patients with chronic airways obstruction. Thorax. 1992;47(12):1019-24.

20. Barrios C, Pérez-Encinas C, Maruenda JI, Laguía M. Significant ventilatory functional restriction in adolescents with mild or moderate scoliosis during maximal exercise tolerance test. Spine (Phila $\mathrm{Pa}$ 1976). 2005;30(14):1610-5.

21. Sperandio EF, Alexandre AS, Yi LC, Poletto PR, Gotfryd AO, Vidotto MC, et al. Functional aerobic exercise capacity limitation in adolescent idiopathic scoliosis. Spine J. 2014;14(10):2366-72.

22. Bas P, Romagnoli M, Gomez-Cabrera MC, Bas JL, Aura JV, Franco N, et al. Beneficial effects of aerobic training in adolescent patients with moderate idiopathic scoliosis. Eur Spine J. 2011;20(Suppl 3):415-9.
23. Katch FI, McArdle W, Katch VL. Fundamentos De Fisiologia Do Exercício. 2nd ed. Rio de Janeiro: Guanabara Koogan; 2002.

24. Tsiligiannis T, Grivas T. Pulmonary function in children with idiopathic scoliosis. Scoliosis. 2012;7(1):7.

25. Canavese F, Turcot K, Holveck J, Farhoumand AD, Kaelin A. Changes of concave and convex rib-vertebral angle, angle difference and angle ratio in patients with right thoracic adolescent idiopathic scoliosis. Eur Spine J. 2011;20(1):129-34.

26. Delorme S, Violas P, Dansereau J, De Guise J, Aubin CE, Labelle H. Preoperative and early postoperative threedimensional changes of the rib cage after posterior instrumentation in adolescent idiopathic scoliosis. Eur Spine J. 2001;10(2):101-6.

27. Johnston CE, Richards BS, Sucato DJ, Bridwell KH, Lenke LG, Erickson M. Correlation of preoperative deformity magnitude and pulmonary function tests in adolescent idiopathic scoliosis. Spine (Phila Pa 1976). 2011;36(14):1096-102.

28. Takahashi S, Suzuki N, Asazuma T, Kono K, Ono T, Toyama Y. Factors of thoracic cage deformity that affect pulmonary function in adolescent idiopathic thoracic scoliosis. Spine (Phila Pa 1976). 2007;32(1):106-12.

29. Smiljanić I, Kovač V, Čimić M. Changes in pulmonary functional parameters after surgical treatment of idiopathic scoliosis. Coll Antropol. 2009;33(Suppl 2):145-52.

30. Lowe TG, Edgar M, Margulies JY, Miller NH, Raso VJ, Reinker KA, et al. Etiology of idiopathic scoliosis: current trends in research. J Bone Joint Surg Am. 2000;82A(8):1157-68.

Received on $06 / 07 / 2016$ Recebido em 07/06/2016

Approved on 09/18/2017 Aprovado em 18/09/2017 